\title{
Identification of Learning Styles and Automatic Assignment of Projects in an Adaptive e-Learning Environment using Project based Learning
}

\author{
Luis Alfaro ${ }^{1}$, Erick Apaza ${ }^{2}$, Jorge Luna-Urquizo ${ }^{3}$, Claudia Rivera ${ }^{4}$ \\ Universidad Nacional de San Agustín de Arequipa, Arequipa - Perú
}

\begin{abstract}
The use of the project-based learning approach is one of the emerging trends in education and Adaptive e-Learning platforms. One of the main challenges in this line of research is to identify the learning style of students, whose results are considered in this work, for the assignment of course projects which best suit the characteristics of each student in particular as they incorporate different types of learning strategies and objects in order to contribute to facilitate and simplify the teaching/learning process of the adaptive e-Learning platform, which uses the project-based learning approach. In this work, after carrying out a review of the literature for the theoretical foundation and establishment of the state of Art, a line module of automatic recognition of learning styles is proposed, which uses the information of the interaction of the student with the system and the one that is based on Neural Networks and Fuzzy Logic, whose results are considered by the module of selection and assignment of projects that uses the Case Base Reasoning, later carrying out the tests and the analysis of the results obtained.
\end{abstract}

Keywords-Adaptive e-Learning; project based collaborative learning; case-based reasoning; learning styles; back propagation neural networks

\section{INTRODUCTION}

Project-based Collaborative Learning (PBCL) is an emerging approach within academia, and "one of the most effective strategies for the teaching/learning process" [1]. According to Lee [2], "the main reason is that it is in accordance with the learning concepts of constructionism, cognitive psychology, and integrated curriculum". From within this approach, each project is defined as a complex task or real problem whose resolution involves research activities, planning, design, and development, among others.

According to [3], "it is opposed to the behaviorist pedagogy which is based on a unilateral and passive transmission of knowledge from the teacher to the student". PBCL places the emphasis on topics of everyday concern, and allows students to "explore and solve problems together with their peers" [2], and it contributes to developing in students the motivation to search for and produce knowledge [4]. However, the application of PBCL in the classroom, within the context of traditional teaching/learning, is a task which poses great challenges due to limitations of physical space, time, planning, and available resources, among others [2]. In this context elearning platforms and environments, under the supervision of teachers or tutors, are constituted as an important alternative for the implementation of and support for the PBCL perspective, thus giving rise to the term 'NetPBL' (Internet ProjectBased Learning) although, like all tools, it is also necessary to consider the use risks associated with this technology [5].

Currently, although there are some platforms which, in their most recent versions, give support to the PBLC perspective, they can only do it in a very basic way, without incorporating other elements of higher relevance, such as the use of collaborative tools and project assignments based on user profiles and learning styles (LS), either in individual or group form, in the case of which the LS, profiles, and cultures of the members of each group must be combined according to the proposed objectives, toward the end of enriching the experience and improving social skills and communication.

The present project proposes a model of selection and course-project assignment as support for the PBCL approach, which takes as input the LS and profiles of the user, previously identified from the students' online interactions [6], and utilizes Case-Based Reasoning techniques to recover and adapt the most adequate projects for a determined group of students. The tests were performed with a group of students at the Universidad Nacional de San Agustín de Arequipa (UNSA).

The rest of this paper is organized as follows, Section II presents a revision of related works. Section III describes the proposed model and its method for the identification of LS. Section IV presents the results achieved from the tests performed. Section V presents conclusions and future recommendations for this work.

\section{RELATED WORKS}

\section{A. Project-based Collaborative Learning}

Project Based Learning (PBL) is a student centered teaching method based on constructivism and constructionism theories developed by Gergen, Piaget, Inhelder and Vygotsky [7]. A review of literature shows that PBL has increasingly been trialed and adopted across a diversity of educational institutions worldwide [8]. A short definition of PBL establishes: "a model that organizes learning around projects". Likewise, the PBL approach is a teaching method by which students acquire knowledge and skills over a period of time, to investigate and answer a question, a problem or a real challenge which can be complex and involving [9]. According to [10], PBL can be defined in three ways: "a process of inquiry, a learning-to-learn approach, and a method for acquiring new knowledge".

Some of the elements of project design [9], include:

- Essential knowledge, comprehension and success skills: the project focuses on the student's learning 
objectives, including basic content and skills such as problem solving, critical thinking, and collaboration.

- A problem or question that constitutes a challenge: the project is framed by a significant problem to be solved or a question to be answered, at an appropriate level of challenge.

- Sustainable research: students engage in a rigorous and lengthy process that consists of asking questions, seeking resources, and applying solutions that come from available information.

- Authenticity: the project presents a context, tasks and tools pattern of quality or real impact, and can also address the concerns, interests, and personal issues of students in their own lives.

- Opinion and possibility of selection of students: Students make decisions about projects, including aspects of how they work, or about what they create.

- Reflection: Students and teachers reflect on the learning and effectiveness of their research activities and projects, the quality of students' work, the emergence of obstacles and how to overcome them.

- Critical review: students give, receive and use feedback to improve their processes and products.

- Product advertising: students publicize the results of their projects, explaining, exhibiting and/or presenting works outside their field of study.

For Maldonado [4], in the PBL model lies the essence of the problem of teaching, showing the student the way to obtain concepts. The projects to be used for learning with a collaborative approach are different from others in aspects such as: They must be student-centered and student-led. They must be clearly defined. They are appropriate. They must connect the student, their personal environment, and the labor competencies. They should provide opportunities for feedback and evaluation by experts. Promote opportunities for reflection and self-assessment. The content should be meaningful to students; which can be directly observable in their environment. Must correlate with real-world problems. Be first-hand research and development. Be sensitive to local culture and culturally.

For [9], learning by means of a project is likely to increase motivation and give the students a sense of satisfaction, it is helpful for developing long-term learning skills, to develop deep, integrated understanding of content and process, it allows students learn to work together to solve problems, and it promotes responsibility and independent learning. In fact, PBL works to integrate and apply:

- $\quad$ Structured new knowledge covered in the course.

- Knowledge learned in other courses.

- Prior life experiential based knowledge.

- New self-taught knowledge.

The unique characteristics and potential of PBL, appropriately incorporated into Adaptive e-Learning environments, will allow the student to interact with learning objects (LO) and resources of the emerging media, which will enrich the learning experiences, making them unique, singular and lasting.

\section{B. Learning Styles (LS)}

Learning, which is a series of biological and psychological processes that occur in the cerebral cortex that, thanks to the mediatization of thought, lead the subjects to modify their attitude, ability, knowledge and information, as well as their forms of execution, through the experiences they acquire in the interaction with the external environment, in search of adequate answers. In this perspective, knowledge about different LS is a crucial element for teachers, educational institutions and especially for the design of teaching/learning systems supported by emerging technologies. All individuals have their own style for learning new facts, and there is a great diversity of such LS, which require specific instruments to be identified. In this perspective, there are several models that allow us to identify these characteristics of each individual's LS. For the development of this work it is necessary to review the works of some classic authors of this approach.

On the other hand, according to [11], two dimensions are necessary for learning to occur. The first is described as perception of the medium and the second as processing. Likewise, the author affirms that LS are relatively stable modes according to which individuals acquire and process information in order to act and solve problems. In this way, he says that in order to learn it is necessary to have four basic capacities: concrete experience (CE), reflective observation (RO), abstract conceptualization (AC) and active experimentation (AE).

Students learn in different ways; they have individual preferences and ways of how they perceive and process information. These individual preferences are called LS. In [11], defines them as "personal qualities that influence students' abilities to acquire information, interact with others, and enabling them to participate in learning experiences".

Fewster [12] relied on the experiential learning theory to classify LS. Starting from the idea that learning and transforming experience into knowledge, the author developed an Inventory of LS, which consists of a self questionnaire with a series of questions about how people learn. Thus, the experiential learning cycle derives four LS: divergent, convergent, assimilators and accommodators.

One of the models derived from Kolb's theory is that of Honey-Alonso [13]. According to this, learning and human behavior result from the interaction between the environment, the previous experience lived by the adult learner and the individually constructed knowledge. Thus, there is a strong correlation between Kolb's and Honey-Alonso's styles. In Honey-Alonso model [14], establish four types of apprentices:

- Active Style: they appreciate new experiences, have an open mind and are enthusiastic about new tasks. The adjectives applied to this style are: animators, improvisers, discoverers, open to risk, spontaneous.

- Reflective Style: they like to consider an experience from different perspectives, among other attributes. The adjectives that are applied to this style are: pondered, conscious, receptive and analytical. 
- Pragmatic style: they like to put ideas into practice. The adjectives applied to this style are: experimental, practical, direct, effective and realistic.

- Theoretical Style: Facing problems in a logical way. The adjectives applied to this style are: methodical, logical, objective, critical and structured.

In the context of this research project, LS are defined as the form in which each individual selects, obtains, and processes information in the most adequate way for them, according to their individual characteristics and aptitudes. There are currently diverse models or learning-style classification, with 71 models already having been identified [15]. Therefore, it must be considered that each teaching system, according to the model followed, utilizes different methods in order to obtain and identify the LS of each student [16], those being the automatic models utilized in the authors' line of research, taking as a point of reference Honey model [17], because it is centered on how information is perceived and processed, while similiar approaches center on other aspects which are not so relevant from the point of view of e-learning platforms.

If each LS has particular characteristics such as those mentioned above, which can be observed in the way each student learns, it is logical to assume that there are methodological strategies that benefit learning more according to each student's own style. One of the greatest challenges in the design and development of adaptive e-Learning systems is to include the methodological strategies that best suit each type of learner.

\section{Case-based Reasoning (CBR)}

The CBR is a process that involves the reuse of past experiences, and was used in expert systems and cognitive science. In this approach, the user trying to solve a new problem recognizes similarities with previously solved problems called cases. A case is a commonly specific problem that has been identified, resolved, stored and indexed in a memory with the solution, and optionally the process for obtaining [18].

A case is basically an experience of a solved problem. This can be represented in many different ways. A case base is a collection of such cases. The term-based means that the reasoning is based on cases, that is, cases are the first source for reasoning. The term most characteristic of the approach is reasoning. It means that the approach is intended to draw conclusions using cases, given a problem to be solved. Case based reasoning is an Artificial Intelligence approach adopted by various systems in various problem domains. There are several experiences applied to [19]:

- Classification: select the class to which an entity be appropriate.

- Diagnosis: Select what the analysis of a problem is.

- Prediction: Answered what happens in the future.

- Planning: select an order of activities to a given goal.

- Configuration: Select technical features to included.

Other experiences in literature of the area report diverse applications, such as e-Learning, in which CBR is approached as a solution to an adaptation problem. The objective of the
CBR approach is to solve a current objective problem called "objective case", through the use of a similar solved problem called "source problem" and its solution "source solution". The pairs (sourceProblem, sourceSolution) are called "source cases" and the set of source cases is called "Base cases". This resolution process can be modeled using a five-phase static cycle, using a knowledge base of the problem domain [20]:

- Elaborate: reformulate a clear description of the target case from the application submitted.

- Recover: extract cases similar to the description of the problem to be solved.

- $\quad$ Reuse: select the appropriate case for the target case of the recovered cases and reuse it as a solution.

- Review: evaluate the proposed solution (this can be: accepted, corrected or rejected).

- Retain: store final solution as a new case for future use.

For Lopez [21], the process described above at the knowledge level can be instantiated in different CBR systems. In doing so, different CBR system typologies can be considered according four criteria: knowledge source, function, organization, and distributiveness. On the other hand, RS can be considered as one of the areas of CBR application with greater impact that present challenges for research and application [22], such as the determination of the similarity of a product, which can become a complex issue when conventional product descriptions are not available or when they are incomplete when extracting unstructured information and noise from available information, in the opinions of users, treated through the analysis of feelings.

For [23], RS predict users' preferences over a large number of items by pooling similar information from other users or items when observations are sparse, which are particularly useful in personalized prediction. It has become an essential part of e-commerce, with applications in movie rentals, restaurant guides, book recommendations and personalized e-news, for these considerations, it is that another perspective for the treatment of this research work may be the approach of RS.

The recommender systems (RS) take into account not only information about the users but also about the items they consume; comparison with other products, and so on and so forth. Nevertheless, there are many algorithms available to perform a RS. For instance:

- Popularity, where only the most popular items are recommended.

- Collaborative Filtering, which looks for patterns in the user activity to produce user-specific recommendations.

- Content-based Filtering, the recommendation of items with similar information the user has liked or used in the past (description, topic, among others).

- Hybrid Approaches, combines the two algorithms mentioned above. 


\section{Model System DeVelopment}

The proposed model was developed as an extension of the Moodle open source LMS, to which two intelligent modules were added, which will be described in the following sections.

\section{A. Automatic Learning-style Recognition Module}

The automatic LS identification module, take as reference the Honey-alonso LS model [24] . This model in particular was used as opposed to others, such as the proposals described in Kolb [25], Vincent [26], etc., due to the fact that it centers on "how information is perceived and processed by the user", an especially important factor in LMS platforms. The development of this module was carried out in three stages:

1) Collection of Experimental Data: experimental data were obtained through the application of the test of Honey [24], to 34 students in the School of Marketing - UNSA, being the only group enrolled during that semester in that course, which had been implemented on the platform since before the beginning of the semester. Fig. 1 shows the results of the test, where it is possible to appreciate that, in a high percentage of cases it is not possible to determine a predominant LS.

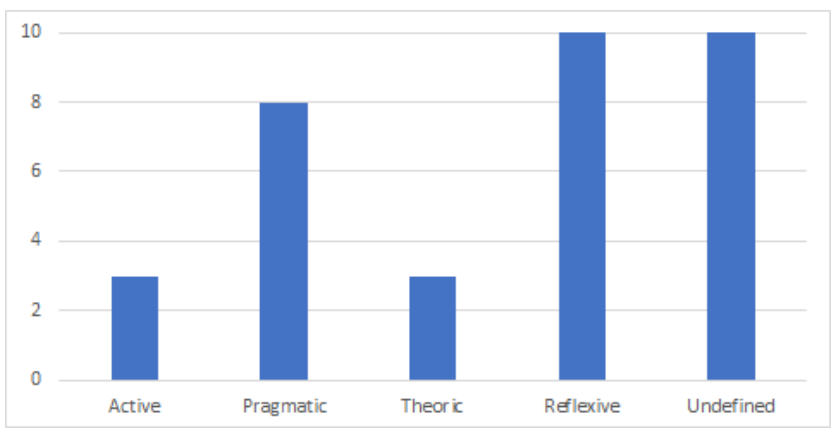

Fig. 1. Test data results obtained

The data collected through the traditional method (test) were utilized for the validation of the authors' research hypothesis, comparing it with the results obtained by the NN. For this purpose, the data were divided into two sets, procuring that both sets maintain similarity with those that were utilized as training and test sets in the development of the NN.

2) Pre-processing of inputs: in the first tests, some deficiencies were found in the results obtained by the NN. The analysis of these incidents led to determine two factors that directly influenced the results, these are:

- The "noise" within the NN input-data sets.

- The input data in which it is difficult to determine a single output.

In order to reduce the impact of the issues in the performance of the proposed model, the authors the authors decided to add a pre-processing phase of the input data to the $\mathrm{NN}$ by way of a fuzzy set (FS) which "represents a better categorization of the students preferences for a determined type of resources" [1], taking into consideration the percentage and relevance of the students interactions in each one of the resource categories. This change is justified on the premise that determining the student's specific LS can turn into a fuzzy-nature problem due to the fact that "important situations and characteristics must be considered with a certain level of imprecision" [1]. This means that students' categories are ultimately created with imprecise limits and cannot be well-defined, allowing one to treat the problem with only an approximation of reality, especially when cognitive and subjective aspects are considered.

For the analysis and classification of user interactions, the proposed model defines 20 resource categories, according to the resources available in the Moodle platform, in such a way that each and every student selection (click) could be could be taken into account in a log-file and, therefore, a register of his/her preferences stored. Each one of these categories was related to the Honey-Alonso model through the application of fuzzy logic techniques related to the "theoric and behavioral characteristics associated with each LS", as proposed by [1].

3) LS identification: based on an backpropagation NN, composed of an input layer, a hidden layer, and an output layer (see Fig. 2). The main reason for the utilization of this model was that it allowed for the "training of weights of a NN with an undetermined number of layers" [1], an feature which makes it possible to utilize differentiable transference functions in order to execute approximation functions, association, and classification tasks.

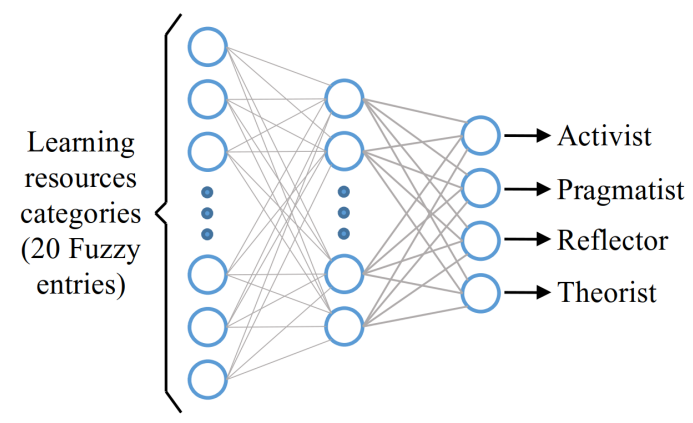

Fig. 2. Neural Network architecture. Source: [6]

The input neurons represents the resource categories defined in [6], which have as input value "the percentage of the interactions within a particular category as a value between 0 and 1" [1], obtained from the log-file. The value 0 indicates that the student did not choose any type of the resource category, and the value 1 indicates that the student only utilizes resources of that category.

During the initial runs with the NN, some problems were discovered in the efficiency of and the results obtained from the NN training session, which according to the analysis conducted correspond to the cases in which the user's responses or interactions do not allow for the clear identification of a single LS, either because of the closeness of all the values or because of multiple outputs with the same value, a situation which complicates the adjustment of weights in the NN and, therefore, the results obtained. This could also have something to do with the mixed and disperse preferences in some students. Two of these cases which are most representative of the phenomenon just described are shown in Table I.

To reduce the impact of these inconveniences, a prepro- 
TABLE I. NOISE EXAMPLES

\begin{tabular}{|c|c|c|c|}
\hline Activist & Reflector & Theorist & Pragmatist \\
\hline 14 & 16 & 15 & 17 \\
\hline 15 & 15 & 13 & 15 \\
\hline
\end{tabular}

cessing phase of the inputs based on fuzzy logic techniques was included, with the objective of achieving a more precise categorization of student preferences regarding the categories of learning resources, taking considering the percentage and importance of their interactions with the LMS.

\section{B. CBR-based Project Selection and Assignment}

The architecture shown in Fig. 3, corresponds to the model based on the application of CBR techniques. For [1], the projects of the courses are associated with "cases" from the perspective of the PCBL being able to define the problem in the following way: What is the project that should be assigned to a student or group of students, who have a learning style according to an established learning objective?.

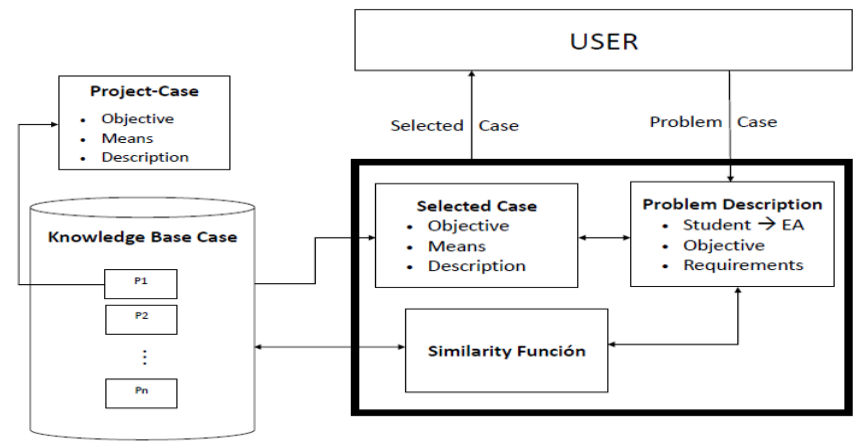

Fig. 3. CBR model architecture.

The starting point for the implementation of the techniques was the open source tool J-Colibri, which presents a layered architecture, and Colibri Studio. The methodology used to solve the problem consists of five steps or tasks:

1) Representation of cases (Fig. 4): Previous experiences are represented by a case, which could be projects that come from previous years, similar courses, etc., which must contain the knowledge that the reasoning model required for its operation. The set of previous cases is called chaos library or case base. A project or case must have at least the following attributes: (i) the problem: this represents the competencies that the student must develop, (ii) the solution: which is described in the project for the resolution of a problem or requirement described above, (iii) the LO and resources available for the execution of the project, (iv) characteristics required or suggested for the team members, which could include LS, (v) other limitations or restrictions.

2) Case recovery: Using some measure of similarity, the current problem should be compared or compared with the problems stored in the base of cases, with the objective of establishing the relevance of the same one, to finally recover the project more similar

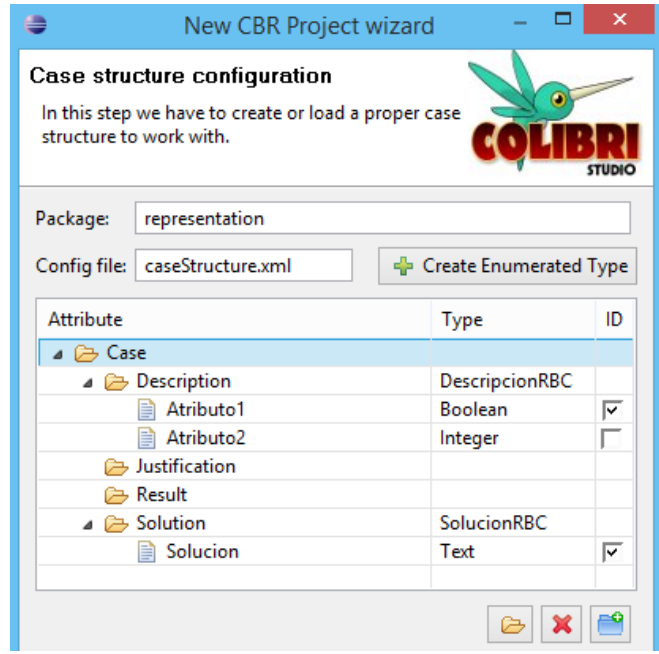

Fig. 4. Definition of Case structure

to the proposed problem. For comparison measures, averages, etc., a relative weight will be established for each of the attributes, according to their importance in the selection of course projects, with the adequate establishment of similarity measures for the selection of course projects constituting an element of great importance, as shown in Fig. 5.

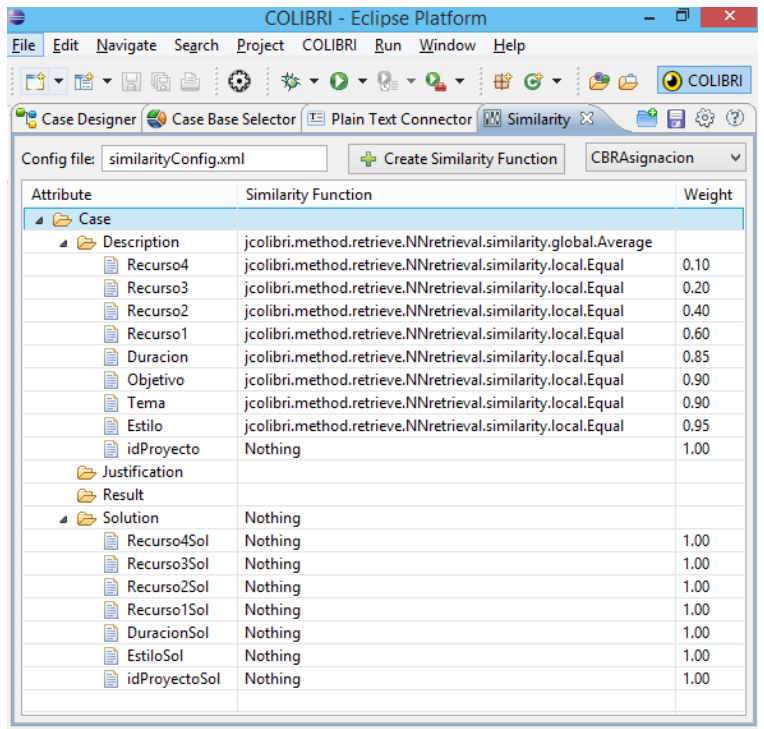

Fig. 5. Case attributes, similarity functions and weights.

3) Reuse of cases: The cases recovered for the resolution of the current problem must be copied and integrated, also formulating a new project in accordance with the objectives and requirements raised. This phase is also known as case adaptation. It can be developed in three ways: substitution, transformation and generative adaptation.

4) Case review: It consists of evaluating the solution originated in the reuse or adaptation phase in the resolution of the new case. It is generally carried out by the experts of the domain. If the solution requires 
some adjustment, the solution is repaired iteratively until it is validated.

5) Retention of cases: When a new solution is validated by experts, the new case is stored in the case base with clearly defined criteria for future use, thus increasing the case base, which will allow a greater repertoire of new solutions. It is necessary to emphasize that a greater number of stored cases has a direct impact on the new solutions, which will also be increasingly complete and precise.

In the context of the proposed platform, a LO is defined as a digital material with different granularity, which can be used for educational purposes from an intentionality that is defined implicitly or explicitly by educational objectives, and contains metadata that allow its description and retrieval, facilitating its reuse and adaptation to different environments, among which the following can be used: the theme, pedagogical style, format, difficulty level, age range or copyright restrictions, and may also include keywords, descriptors, among others.

In this way, a typical query, as shown in Fig. 6, is based on the student's learning style, taken as input from the output of the automatic identification of learning styles module, the topic to be resolved, the learning objective, the duration of the project, the available resources or LO that are accessed in the online repository, among other attributes.

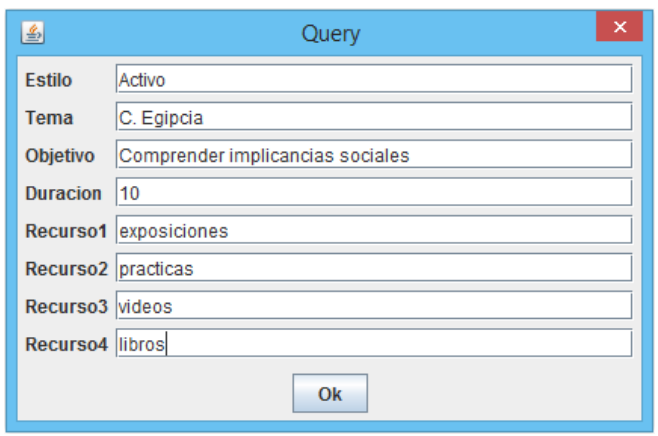

Fig. 6. Example of RBC query.

In the proposed model, the comparison of the attributes is performed using a linear similarity function, according to the procedure detailed in [1].

\section{RESULTS}

\section{A. Results of the Learning-styles-identification Module}

For the tests of this module, students perform a series of activities throughout a semester. According to [1]: "the identification must be made throughout a period of utilization time, given that the data analyzed in just one session might be seen as influenced by various factors". Fig. 7 presents the identification of the LS of four students throughout each week, where it can be appreciated that, for the 'case-1' student, the identification realized in weeks 3 and 20 might indicate that the student fits into the second category, however, it is clear that this student instead fits into the first category.

This result is understandable due to the proximity among some LS and the mixed preferences of some students. For

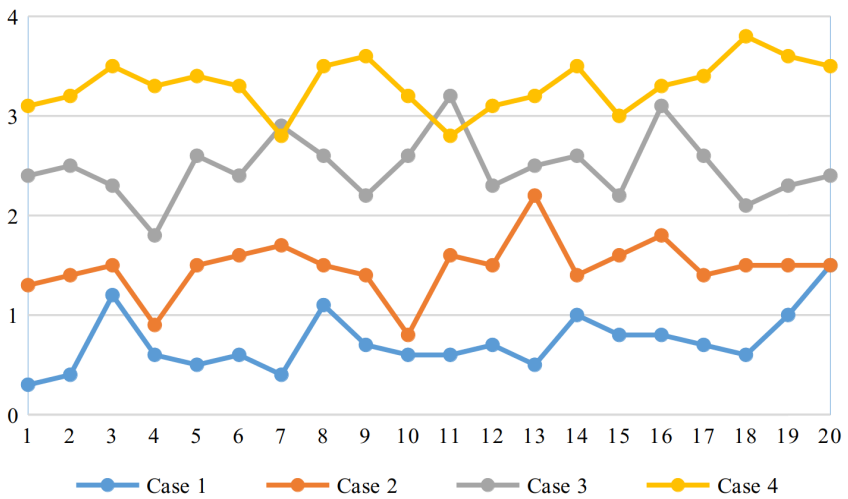

Fig. 7. Identification of LS of four students throughout time. Source: [6]

this reason, the best option would be to identify the LS during some introductory course or previous activities, before initiating the adaptation tasks and content personalization of the LMS, and refine iteratively in the following activities or courses throughout the student's training process.

For the tests of this model, the users' interactions, which were obtained through the LMS, and the test data, collected through the traditional method (test), were utilized, having been divided into two data sets:

- Training set: utilized for the training of the NN, to determine the parameters (weights) of the hidden layer's neurons. For this, user responses to the questionnaire are utilized, correlated with the resource categories proposed as input data. The network is trained in order to obtain the same result as the traditional method, which is to say the tabulation of responses to the questionnaire, which were known beforehand.

- Test set: utilized in order to compare the results obtained by the NN based on user interactions in the platform, as input, with the LS previously identified for the same group of users.

The results obtained by the NN had a $76.5 \%$ of coincidence with the results collected under the traditional method, for which the proposed model is considered to have reached a $76.5 \%$ of efficiency. Table II shows a comparison of the distinct approaches proposed for the automatic identification of LS, taking into consideration the models or learning-style schemes utilized in each approach. It must be pointed out that in the case of the approaches where the efficiency for each LS in isolation is calculated, the average of the same ones as a measurement of global efficiency has been considered with the objective of facilitating the comparison between the distinct approaches.

\section{B. Results of the Selection-module Tests and Project Assign- ment}

For this tests, 50 case-retrieval queries were conducted according to the procedure shown in Fig. 6, taking as principal search criteria the learning objective, the problem to solve, project duration, and the LS. These queries were conducted utilizing a case base defined in a general way by LS and LO specialists, obtaining a state of affairs in which for $80 \%$ of the queries the module could find at least 3 similar cases and 
TABLE II. COMPARISON OF EVALUATED MODELS. SOURCE: [6]

\begin{tabular}{|l|c|c|}
\hline Evaluated techniques & Learning Styles model & Efficiency \\
\hline Bayesian networks & Felder \& Silverman & $66 \%$ \\
\hline NBTree y CRB & Felder \& Silverman & $67.5 \%$ \\
\hline Genetic algorithms and K-NN & Ad-hoc & $96 \%$ \\
\hline Monitoring of interactions & Felder \& Silverman & $79.6 \%$ \\
\hline LOs and time estimation & Felder \& Silverman & $69.6 \%$ \\
\hline NN and navigation maps & Vincent \& Ross & $90 \%$ \\
\hline Stochastic models & Felder \& Silverman & $70 \%$ \\
\hline NeuroFuzzy model (Proposal) & Honey \& Mumford & $77.1 \%$ \\
\hline
\end{tabular}

at least one of them with a similarity measurement superior to $80 \%$ (see Fig. 8), where the alternatives are ordered from greatest to least according to the degree of similitude.

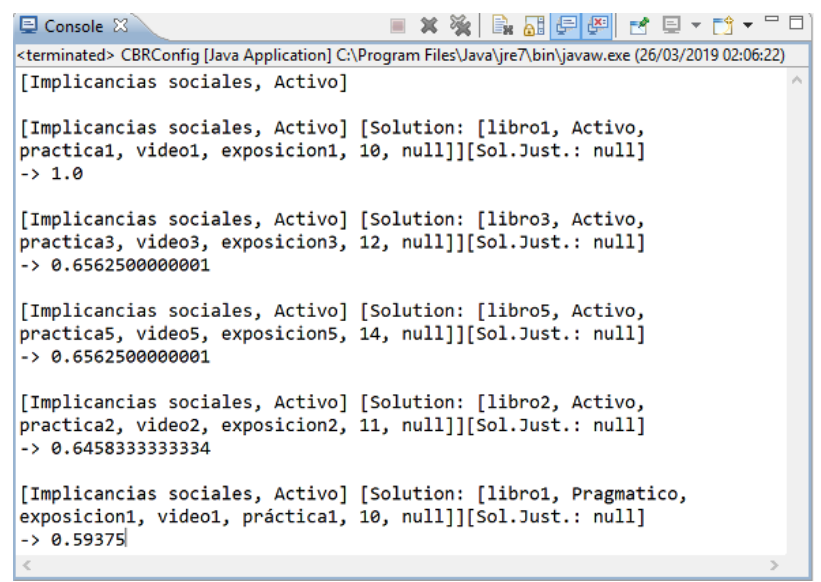

Fig. 8. Results of example query for project assignment. Source: [6]

Table III shows the summary of the tests conducted and the best similitude value obtained for each one of them, utilizing the comparison by linear similitude, in which it can be appreciated that the results are highly acceptable.

TABLE III. RESULTS OF RBC TEST QUERYS

\begin{tabular}{|c|c|c|c|c|c|}
\hline Test & Result & Test & Result & Test & Result \\
\hline 1 & $85 \%$ & 18 & $84 \%$ & 35 & $93 \%$ \\
\hline 2 & $81 \%$ & 19 & $74 \%$ & 36 & $81 \%$ \\
\hline 3 & $100 \%$ & 20 & $88 \%$ & 37 & $61 \%$ \\
\hline 4 & $82 \%$ & 21 & $94 \%$ & 38 & $88 \%$ \\
\hline 5 & $91 \%$ & 22 & $78 \%$ & 39 & $84 \%$ \\
\hline 6 & $69 \%$ & 23 & $81 \%$ & 40 & $100 \%$ \\
\hline 7 & $100 \%$ & 24 & $80 \%$ & 41 & $80 \%$ \\
\hline 8 & $80 \%$ & 25 & $68 \%$ & 42 & $95 \%$ \\
\hline 9 & $87 \%$ & 26 & $100 \%$ & 43 & $85 \%$ \\
\hline 10 & $92 \%$ & 27 & $83 \%$ & 44 & $77 \%$ \\
\hline 11 & $84 \%$ & 28 & $90 \%$ & 45 & $82 \%$ \\
\hline 12 & $72 \%$ & 29 & $86 \%$ & 46 & $83 \%$ \\
\hline 13 & $82 \%$ & 30 & $80 \%$ & 47 & $91 \%$ \\
\hline 14 & $86 \%$ & 31 & $57 \%$ & 48 & $87 \%$ \\
\hline 15 & $91 \%$ & 32 & $87 \%$ & 49 & $80 \%$ \\
\hline 16 & $100 \%$ & 33 & $100 \%$ & 50 & $66 \%$ \\
\hline 17 & $66 \%$ & 34 & $95 \%$ & & $\%$ \\
\hline
\end{tabular}

The objective of this work is to integrate the LS identification module, based on Fuzy $\mathrm{NN}$ and user behavior analysis, with the RBC-based project selection module, so that, according to the student's profile, it is possible to assign projects that have the structure, learning objectives, and what best contributes to user interaction in the LMS, and thus enable more meaningful learning using the PBL approach. It would be convenient to subsequently add experimental data corresponding to several semesters or courses, in order to analyze the real impact of the proposal in the learning process.

\section{CONCLUSIONS AND RECOMMENDATIONS}

\section{A. Conclusions}

A subsystem was proposed online, of automatic recognition of LS that uses the information of the interaction of the student with the system, and is based on NN and Fuzzy Logic, whose tests and comparison, with works carried out by other groups of investigation is quite satisfactory. Likewise, a subsystem was proposed and developed based on CBR, which allowed an assignment of projects, with quite high relevance of percentages in relation to the LS and profiles of the students.

Likewise, the design and incremental development of the Hybrid adaptive e-Learning system model that uses the PBL approach has a high degree of customization for the assignment of projects and LOs that correspond to the personal characteristics of the learner, contributing to facilitate and simplify the teaching/learning process of the adaptive e-Learning platform.

Finally, the use of a neurofuzzy NN and the CBR techniques, allowed an original approach to the treatment of this complex problem, obtaining satisfactory results.

\section{B. Recommendations}

It is necessary to broaden the base of cases with information from future semester courses, for the realization of new tests, which will allow a better analysis of the results obtained.

It is necessary to explore the possibilities of incorporating the students thinking styles to the Adaptive e-Learning model.

Finally, it is necessary to explore the possibilities of incorporating the resources of Immersive Virtual Reality and Augmented Reality to the adaptive e-Learning model, so that the interaction with the LOs does not have linguistic, symbolic and/or computational mediation, which necessarily incorporates reflection, a fact that does not contribute to students building their knowledge through direct experiences.

\section{ACKNOWLEDGMENT}

The authors would like to thank the Universidad Nacional de San Agustín de Arequipa, for supporting this research.

\section{REFERENCES}

[1] L. Alfaro, C. Rivera, and J. Luna-Urquizo, "Using project-based learning in a hybrid elearning system model," International Journal of Advanced Computer Science and Applications, vol. 10, no. 10, 2019.

[2] C.-I. Lee and F.-Y. Tsai, "Internet project-based learning environment: the effects of thinking styles on learning transfer," Journal of Computer Assisted Learning, vol. 20, pp. 31-39, feb 2004.

[3] F. Abdallah, C. Toffolon, and B. Warin, "Models transformation to implement a project-based collaborative learning (PBCL) scenario: Moodle case study," in 2008 Eighth IEEE International Conference on Advanced Learning Technologies, IEEE, 2008. 
[4] M. Maldonado, "Aprendizaje basado en proyectos colaborativos. una experiencia en educacion superior," Laurus - Revista de Educacion, vol. 14, no. 28, pp. 158-180, 2008.

[5] D. M. Verstegen, N. de Jong, J. van Berlo, A. Camp, K. D. Könings, J. J. van Merriënboer, and J. Donkers, "How e-learning can support pbl groups: A literature review," in Educational technologies in medical and health sciences education, pp. 9-33, Springer, 2016.

[6] L. Alfaro, C. Rivera, J. Luna-Urquizo, E. Castaneda, and F. Fialho, "Utilization of a neuro fuzzy model for the online detection of learning styles in adaptive e-learning systems," International Journal of Advanced Computer Science and Applications, vol. 9, no. 12, 2018.

[7] S. Aldabbus, "Project-based learning: Implementation \& challenges," International Journal of Education, Learning and Development, vol. 6, no. 3, pp. 71-79, 2018.

[8] B. Condliffe, "Project-based learning: A literature review. working paper.," MDRC, 2017.

[9] E. d. S. Zancul, T. T. Sousa-Zomer, and P. A. Cauchick-Miguel, "Project-based learning approach: improvements of an undergraduate course in new product development," Production, vol. 27, no. SPE, 2017.

[10] R. E. Gewurtz, L. Coman, S. Dhillon, B. Jung, and P. Solomon, "Problem-based learning and theories of teaching and learning in health professional education," Journal of Perspectives in Applied Academic Practice, vol. 4, no. 1, 2016.

[11] L. N. R. Agudelo, V. S. Urbina, and F. J. M. Gutiérrez, "Estilos de aprendizaje basados en el modelo de kolb en la educación virtual," Apertura, vol. 2, no. 1, 2010.

[12] L. Fewster-Thuente and T. J. Batteson, "Kolb's experiential learning theory as a theoretical underpinning for interprofessional education," Journal of allied health, vol. 47, no. 1, pp. 3-8, 2018.

[13] R. Rodríguez Cepeda, "The learning models of kolb, honey and mumford: implications for science education," Sophia, vol. 14, no. 1, pp. 51-64, 2018.

[14] A. F. Hoffman and M. F. Liporace, "Cuestionario honey-alonso de estilos de aprendizaje: Análisis de sus propiedades psicométricas en estudiantes universitarios," Summa psicológica UST, vol. 10, no. 1, pp. 103-117, 2013.
[15] F. Coffield, D. Moseley, E. Hall, and K. Ecclestone, Should we be using learning styles? What research has to say to practice. London: Learning and skills research centre, 2004.

[16] A. Klašnja-Milićević, B. Vesin, M. Ivanović, and Z. Budimac, "Elearning personalization based on hybrid recommendation strategy and learning style identification," Computers \& Education, vol. 56, pp. 885899, apr 2011.

[17] P. Honey and A. Mumford, Learning styles questionnaire. Organization Design and Development, Incorporated, 1989.

[18] F.-Z. Berriche, B. Zeddini, H. Kadima, and A. Rivière, "Cbr-mining approach to improve learning system engineering in a collaborative elearning platform.," in COMPLEXIS, pp. 94-101, 2018.

[19] S. Shekapure and D. D. Patil, "Enhanced e-learning experience using case based reasoning methodology," Int. J. Adv. Comput. Sci. Appl.(IJACSA), vol. 10, no. 4, pp. 236-241, 2019.

[20] A. Soundoss, G. Mohamed, and F. Abdelhadi, "Case-based reasoning for e-learning systems: State of the art," in 2018 IEEE 5th International Congress on Information Science and Technology (CiSt), pp. 353-356, IEEE, 2018.

[21] B. López, "Case-based reasoning: a concise introduction," Synthesis lectures on artificial intelligence and machine learning, vol. 7, no. 1, pp. 1-103, 2013.

[22] D. B. Leake, B. Smyth, and R. Weber, "Guest editors' introduction: special issue on case-based reasoning," Journal of Intelligent Information Systems, vol. 46, no. 2, pp. 235-236, 2016.

[23] B. Dai, J. Wang, X. Shen, and A. Qu, "Smooth neighborhood recommender systems," The Journal of Machine Learning Research, vol. 20, no. 1, pp. 589-612, 2019.

[24] C. Alonso, D. Gallego, and P. Honey, Los estilos de aprendizaje. Procedimientos de diagnóstico y mejora. Bilbao: Mensajero, 1994.

[25] D. A. Kolb, Experiential learning: Experience as the source of learning and development. FT press, 2014.

[26] A. Vincent and D. Ross, "Personalize training: determine learning styles, personality types and multiple intelligences online," The Learning Organization, vol. 8, pp. 36-43, mar 2001. 